Supporting Information

\title{
Real-Time Single-Molecule Imaging of the Spatial and Temporal Distribution of Reactive Oxygen Species with Fluorescent Probes: Applications to $\mathrm{TiO}_{2}$ Photocatalysts
}

\author{
Kazuya Naito, Takashi Tachikawa, Mamoru Fujitsuka, and Tetsuro Majima* \\ The Institute of Scientific and Industrial Research (SANKEN), Osaka University, Mihogaoka 8-1, \\ Ibaraki, Osaka 567-0047, Japan
}

\section{Contents}

Movie S1. Real-Time Single-Molecule Imaging of the Airborne ${ }^{\bullet} \mathrm{OH}$ Diffused from the $\mathrm{TiO}_{2} \cdots \cdots \cdot \mathrm{S} 1$

Movie S2. Real-Time Single-Molecule Imaging of the Lateral Diffusion of ${ }^{\bullet} \mathrm{OH}$ at the Interface

S2. Photocatalytic Activities of Pure and $\mathrm{N}$-doped $\mathrm{TiO}_{2}$ Films under UV and Visible Light Irradiations Studied by Time-Resolved Diffuse Reflectance Spectroscopy S4

S3. The Control of the Relative Humidity and Oxygen Concentration S5

S4. Influences of $\mathrm{O}_{2}$ and $\mathrm{H}_{2} \mathrm{O}_{2}$ on the Formation of ${ }^{\bullet} \mathrm{OH}$ Molecules S6

S5. Estimation of the Diffusion Coefficient of ${ }^{\bullet} \mathrm{OH}$ Molecules Spread on the Cover Glass S7 


\section{Movie S1. Real-Time Single-Molecule Imaging of the Airborne ${ }^{\bullet} \mathrm{OH}$ Diffused from the $\mathrm{TiO}_{2}$}

This movie shows the real-time single-molecule observation of the diffusion of ${ }^{\bullet} \mathrm{OH}$ molecules from the UV-irradiated $\mathrm{TiO}_{2}$ film. The details for the experimental setup of this sample are described in the

text (Figure 1A). The intervening gap between the $\mathrm{TiO}_{2}$ film and the HPF-coated cover glass is $12.5 \mu \mathrm{m}$. The observed area in this movie is about $50 \mu \mathrm{m} \times 70 \mu \mathrm{m}$. This measurement was conducted at room temperature and the relative humidity was maintained at $27 \%$. The oxygen concentration was 20.9 vol\%. The UV irradiation of the film started at $t=14 \mathrm{~s}$. The irradiated region is only in the center of the image (ca. $10 \mu \mathrm{m}$, see Figure $1 \mathrm{C}$ in text). The few fluorescence spots observed before the UV irradiation would be ascribed to the self-oxidation caused by the 488-nm excitation of HPF. After the UV irradiation $(t>14 \mathrm{~s})$, a high number of the fluorescent spots arising from the airborne ${ }^{\circ} \mathrm{OH}$ molecules were observed over the entire region. The quantitative analysis of the detected number of single ${ }^{\circ} \mathrm{OH}$ molecules was discussed in the text (Figure 5).

\section{Movie S2. Real-Time Single-Molecule Imaging of the Lateral Diffusion of ${ }^{\circ} \mathrm{OH}$ at the Interface}

This movie indicates the real-time observation of the lateral diffusion of ${ }^{\bullet} \mathrm{OH}$ molecules at the aircover glass interface. The observed area in this movie is about $50 \mu \mathrm{m} \times 70 \mu \mathrm{m}$. This measurement was conducted at room temperature and the relative humidity was maintained at $24 \%$. The oxygen concentration was $20.9 \mathrm{vol} \%$. The $\mathrm{TiO}_{2}$ film is placed on the right edge of this fluorescence image, and UV irradiated at $t=2 \mathrm{~s}$ in the movie. After the UV irradiation, the fluorescent spots arising from the diffusion of the ${ }^{\bullet} \mathrm{OH}$ molecules emerged from the right edge. This clearly shows the real-time detection of the lateral diffusion of the ${ }^{\bullet} \mathrm{OH}$ molecules. The estimation of the diffusion coefficient at the interface is described below. 


\section{S1. Synthesis and Characterization of Pure and N-Doped $\mathrm{TiO}_{2}$}

Pure and N-doped $\mathrm{TiO}_{2}$ powders were synthesized by a sol-gel method. ${ }^{1-3}$ For the synthesis of pure $\mathrm{TiO}_{2}, 150 \mathrm{ml}$ of Milli-Q water was dropwise added to $38 \mathrm{ml}$ of $97 \%$ titanium tetraisopropoxide (Aldrich Co., Ltd.) at $273 \mathrm{~K}$ with vigorous stirring. After dropping, the stirring was continued for $2 \mathrm{~h}$ at room temperature to complete the hydrolysis. The resulting white precipitate was washed with distilled water several times and then calcined at $673 \mathrm{~K}$ for $6 \mathrm{~h}$. After the calcination, a white, pure $\mathrm{TiO}_{2}$ powder was obtained. In the case of the $\mathrm{N}$-doped $\mathrm{TiO}_{2}$, an aqueous $28 \% \mathrm{NH}_{3}$ solution (Nacalai Tesque, Inc.) was used for the hydrolysis instead of water, resulting in a pale yellow powder after calcination at $673 \mathrm{~K}$ for $6 \mathrm{~h}$. This pale yellow color is ascribed to the N-doping into the $\mathrm{TiO}_{2}$ lattice as previously reported. ${ }^{2}$ The UV-visible diffuse reflectance spectra of pure and $\mathrm{N}$-doped $\mathrm{TiO}_{2}$ films are shown in Figure $\mathrm{S} 1$. These measurements were made by a UV-visible spectrophotometer (Jasco, V-570). A significant absorption in the visible region about $435 \mathrm{~nm}$ was found for the $\mathrm{N}$-doped $\mathrm{TiO}_{2}$. Thus, the $\mathrm{N}$-doped $\mathrm{TiO}_{2}$ is excited at $435 \mathrm{~nm}$, which is the wavelength of the bright line of a mercury lamp. In order to confirm the crystal phase and lattice pattern of the prepared pure and $\mathrm{N}$-doped $\mathrm{TiO}_{2}$ powders, X-ray diffraction $(\mathrm{XRD})$ and TEM measurements have been made using a Rigaku RINT2500 XRD spectrometer using a $\mathrm{K} \alpha \mathrm{Cu}$ source and a Hitachi H-9000 instrument equipped with a tilting device operated at $300 \mathrm{kV}$, respectively. Both $\mathrm{TiO}_{2}$ powders were confirmed to have an anatase structure, although the pure $\mathrm{TiO}_{2}$ powder has a small amount of the brookite phase due to the relatively lower calcination temperature, as reported elsewhere (see Figure S2). ${ }^{4} 5$ The average particle size of the pure and N-doped $\mathrm{TiO}_{2}$ powders was estimated to be $17 \mathrm{~nm}$ from the TEM images.

The pure and $\mathrm{N}$-doped $\mathrm{TiO}_{2}$ films for single-molecule experiments were prepared as follows. The $\mathrm{TiO}_{2}$ powders $(6.0 \mathrm{~g})$ were ground in a mortar for $1 \mathrm{~h}$ with $5 \mathrm{ml}$ of Milli-Q water and $600 \mu \mathrm{l}$ of acetylacetone (Nacalai Tesque, Inc.). The resulting $\mathrm{TiO}_{2}$ paste was cast on a quartz glass plate using a doctor-blade method, and calcined in an electric furnace at $723 \mathrm{~K}$ for $30 \mathrm{~min}$. The thickness of the $\mathrm{TiO}_{2}$ films was estimated to be approximately $30 \mu \mathrm{m}$ based on the SEM measurements (Figure S3). 


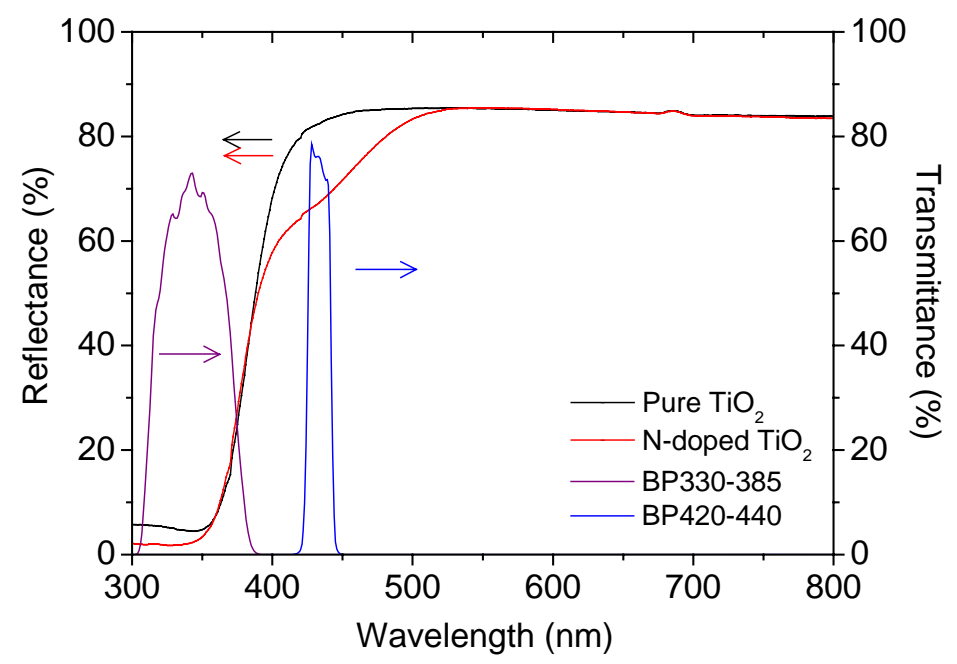

Figure S1. UV-visible diffuse reflectance spectra of pure and $\mathrm{N}$-doped $\mathrm{TiO}_{2}$ films. Transmittance of the band-pass (BP) filters for the 365-nm and 435-nm excitations are also shown.

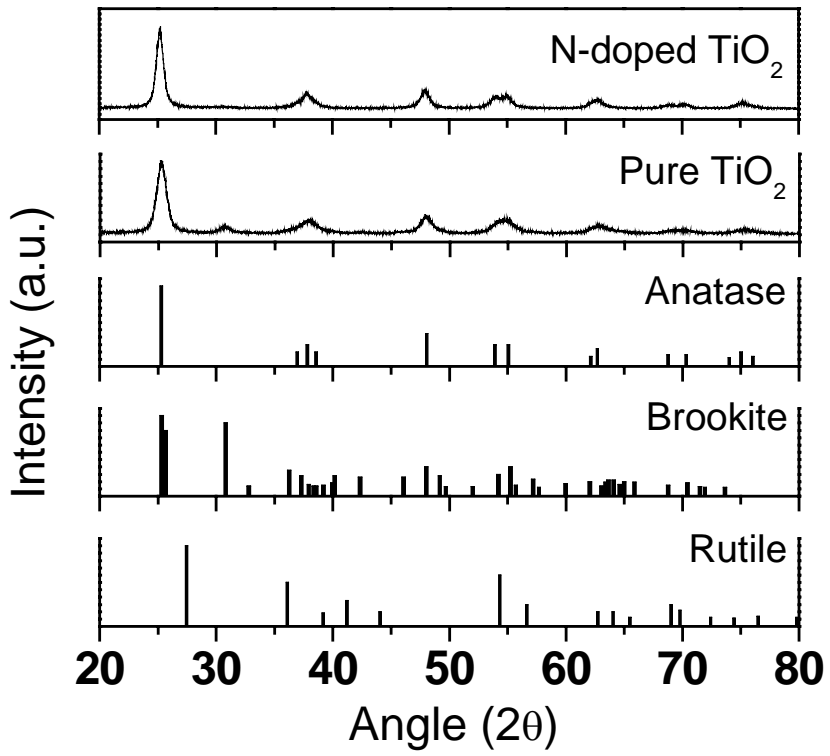

Figure S2. XRD patterns of pure and $\mathrm{N}$-doped $\mathrm{TiO}_{2}$ powders prepared by sol-gel method after calcination at $673 \mathrm{~K}$ for $4 \mathrm{~h}$.

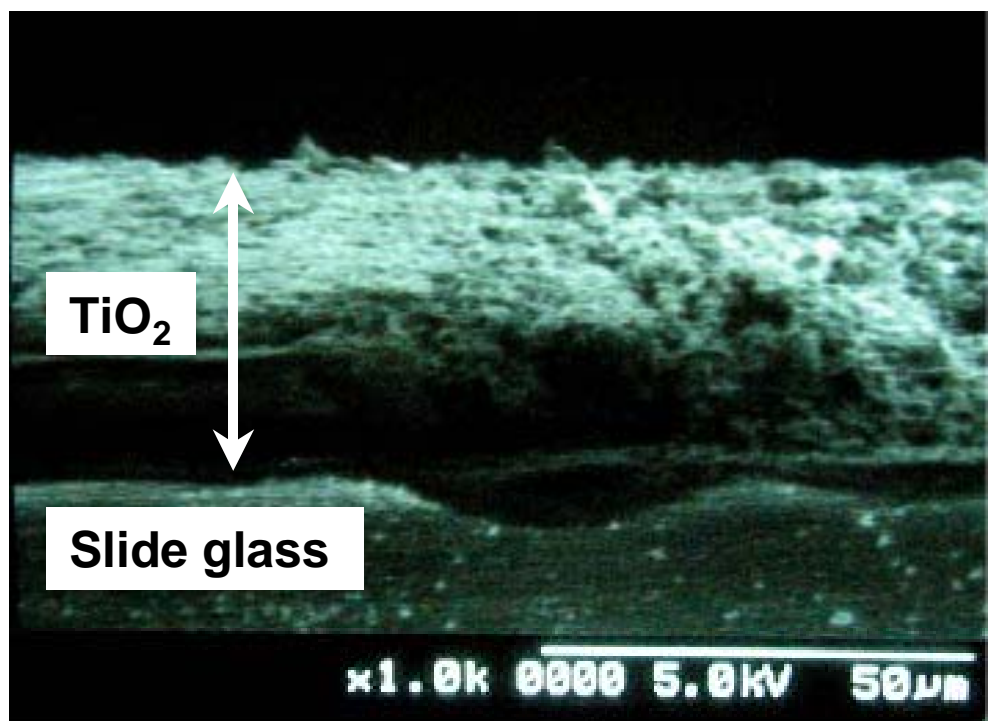

Figure S3. SEM image of the pure $\mathrm{TiO}_{2}$ film coated on slide glass. The thickness was estimated to be approximately $30 \mu \mathrm{m}$. 


\section{S2. Photocatalytic Activities of Pure and $\mathrm{N}$-doped $\mathrm{TiO}_{2}$ Films under UV and Visible Light Irradiations Studied by Time-Resolved Diffuse Reflectance Spectroscopy}

The experimental setup for time-resolved diffuse reflectance measurements is described elsewhere. ${ }^{6}$

Figure S4 shows the transient absorptions at $650 \mathrm{~nm}$ arising from the absorption of the trapped $\mathrm{h}^{+}$and $\mathrm{e}^{-}$for the pure and $\mathrm{N}$-doped $\mathrm{TiO}_{2}$ films under UV- (A) and visible-light irradiations (B).

$\%$ Absorption is given by

$$
\text { \%Absorption }=\frac{\left(R_{0}-R\right)}{R_{0}} \times 100 \text {, }
$$

where $R$ and $R_{0}$ represent the intensities of the diffuse reflected monitor light with and without excitation, respectively.

(A)

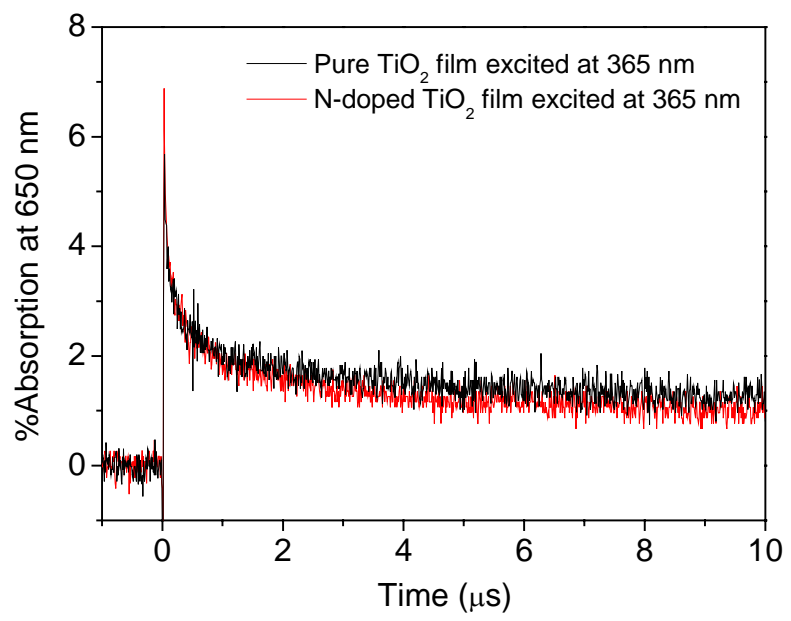

(B)

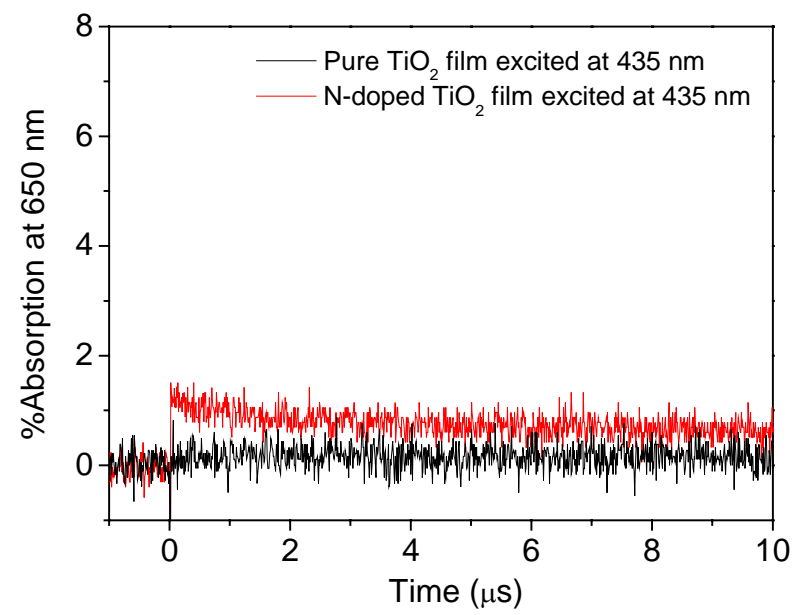

Figure S4. Time-resolved diffuse reflectance spectra of the pure and $\mathrm{N}$-doped $\mathrm{TiO}_{2}$ films under 365-nm (A) and 435-nm excitations (B). (A) The fact that the dynamics and the amount of the carriers of the $\mathrm{TiO}_{2}$ films being almost the same strongly indicates that the photocatalytic activity of the $\mathrm{N}$-doped $\mathrm{TiO}_{2}$ under $\mathrm{UV}$-light irradiation is comparable to that of the pure $\mathrm{TiO}_{2}$. (B) The transient absorption arising from the charge carriers generated by the visible-light irradiation was exclusively observed only for the N-doped $\mathrm{TiO}_{2}$ film. This strongly indicates the photocatalytic activity of the Ndoped $\mathrm{TiO}_{2}$ under visible-light irradiation. 


\section{S3. The Control of the Relative Humidity and Oxygen Concentration}

Fluorescent dyes on a glass are known to randomly diffuse due to the adsorbed water layer, which is sensitive to the relative humidity. ${ }^{7}$ Thus, for the single-molecule detection of ${ }^{\bullet} \mathrm{OH}$, the relative humidity around the sample must be controlled not to enhance the rapid diffusion of HPF on the cover glass, which inhibits the observation of the single-molecule fluorescence. In this study, the relative humidity for the single-molecule fluorescence imaging was maintained at about $20-30 \%$, in which the diffusion of a single-molecule is effectively inhibited in order to recognize as a single-molecule spot.

Also, the oxygen concentration around the sample should be controlled in order to investigate the formation mechanism of ${ }^{\bullet} \mathrm{OH}$ molecules diffused from the UV- and visible-light-irradiated $\mathrm{TiO}_{2}$ films, because $\mathrm{O}_{2}$ plays an important role in the primary process of the $\mathrm{TiO}_{2}$ photocatalytic reactions. ${ }^{8}$

For these purposes, the sample composed of the cover glass and the $\mathrm{TiO}_{2}$ coated-slide glass was enclosed in a glove box. The relative humidity and oxygen concentration inside the box were adjusted by a desiccant and an Ar gas purge, respectively. The relative humidity and oxygen concentration were measured by a Thermo-Hydrometer (As One) and Oxygen Analyzer, $\operatorname{maxO}_{2}+$ (Maxtec, Inc.), respectively. 
(A)

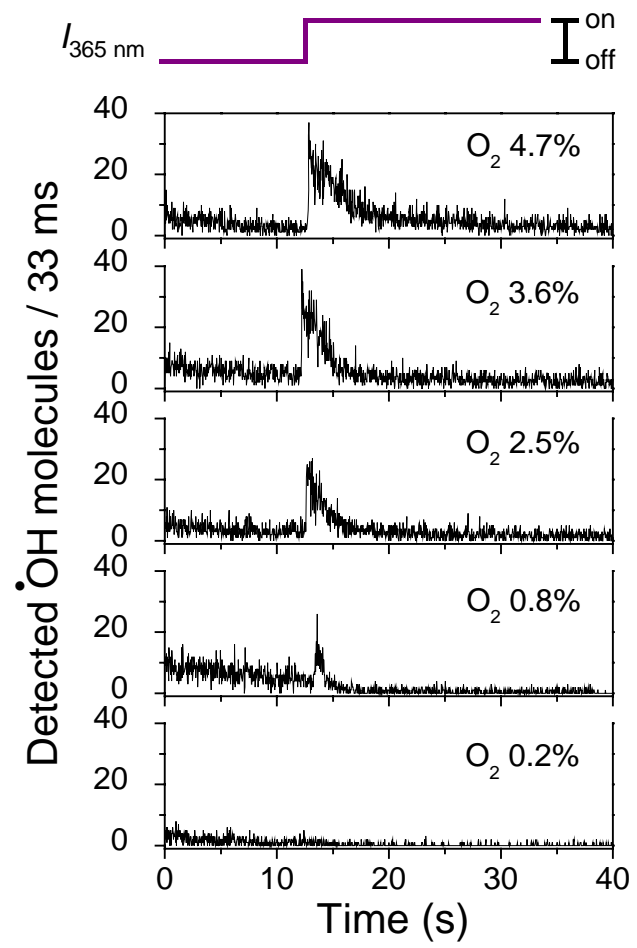

(B)

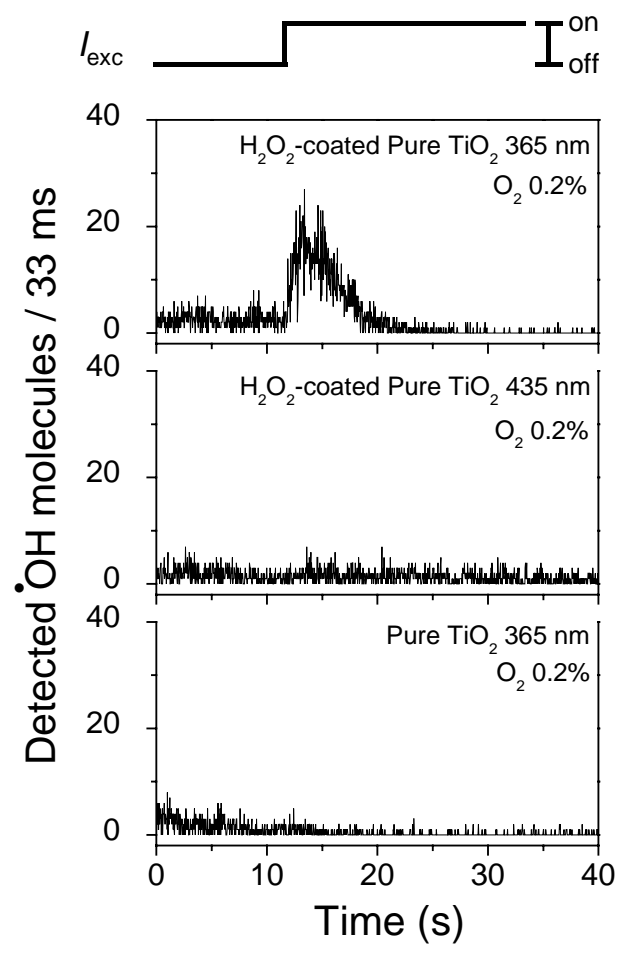

Figure S5. (A) Influences of the concentration of oxygen on the dependence of the detected number of airborne ${ }^{\bullet} \mathrm{OH}$ diffused from the surface of the pure $\mathrm{TiO}_{2}$ film irradiated with $365-\mathrm{nm}$ light. The detected number of airborne $\bullet \mathrm{OH}$ decreased with the decreasing concentration of oxygen. The intervening gap was $12.5 \mu \mathrm{m}$. (B) A comparison of the detected number of airborne - $\mathrm{OH}$ diffused from the surface of the $\mathrm{H}_{2} \mathrm{O}_{2}$-coated pure $\mathrm{TiO}_{2}$ film irradiated with 365-nm (upper) or 435-nm (middle) light. The result for the UV-irradiated pure $\mathrm{TiO}_{2}$ film is also shown (lower). The oxygen concentration was $0.2 \%$.

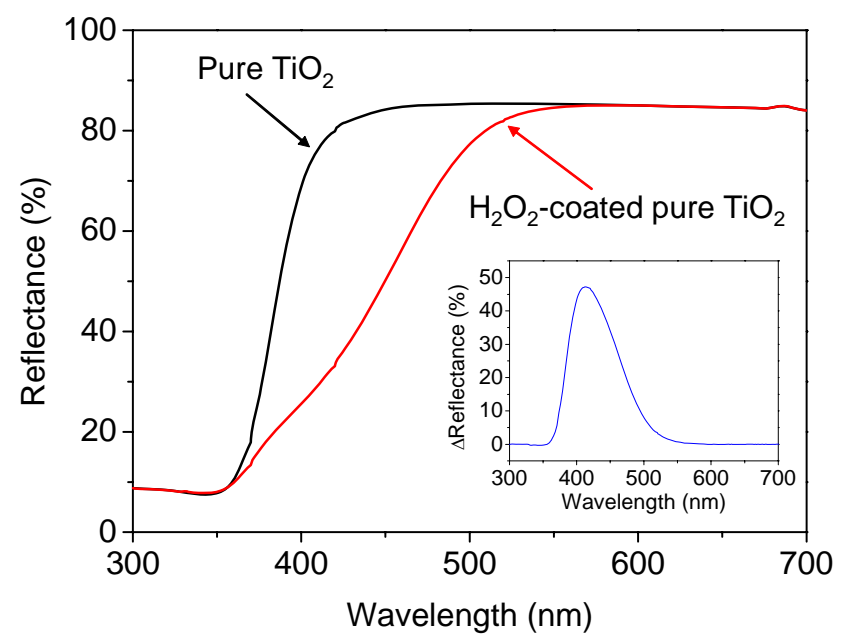

Figure S6. Diffuse reflectance spectra of pure and $\mathrm{H}_{2} \mathrm{O}_{2}$-coated pure $\mathrm{TiO}_{2}$ films. A 30 $\mathrm{wt} \% \mathrm{H}_{2} \mathrm{O}_{2}$ solution was used to prepare the coating film. The visible response due to the $\mathrm{H}_{2} \mathrm{O}_{2}$ coating was clearly observed. Inset is the differential diffuse reflectance spectrum. This peak is probably due to the surface titanium(IV) hydrogen peroxide complexes. ${ }^{9-11}$ 
S4. Estimation of the Diffusion Coefficient of ${ }^{\circ} \mathrm{OH}$ Molecules Spread on the Cover Glass

(A)

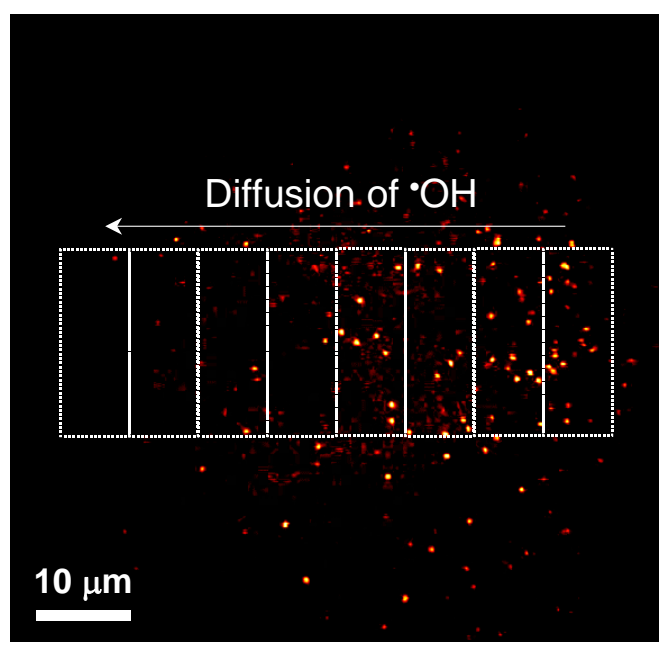

(B)

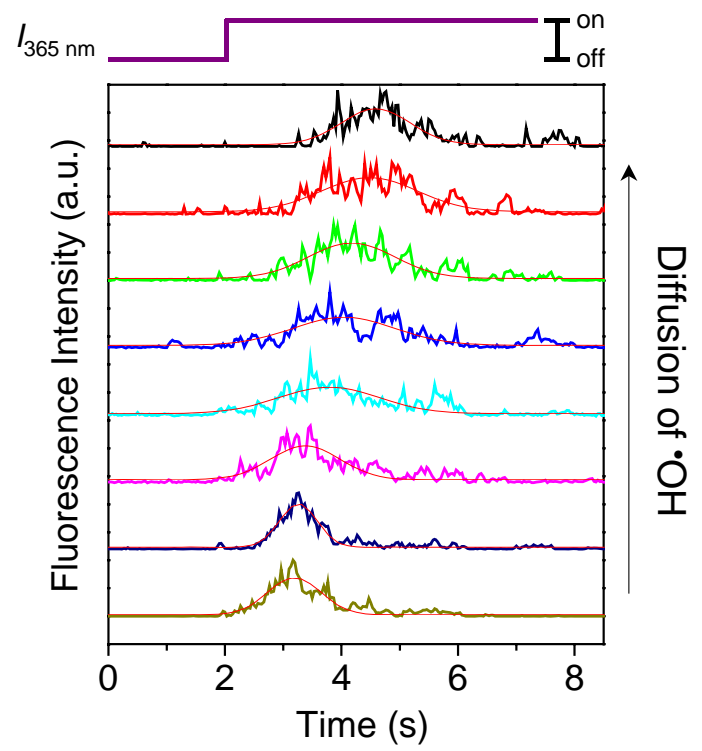

Figure S7. The estimation of the diffusion coefficient of ${ }^{\bullet} \mathrm{OH}$ molecules spread on the cover glass. (A) The fluorescence image during the lateral diffusion was divided into 8 regions along the diffusing direction. The length of the region along the direction is $7.3 \mu \mathrm{m}$. Right edge of the image corresponds to the $\mathrm{TiO}_{2}$ film irradiated by the UV light (Figure 8 in text). (B) Temporal changes in the fluorescence intensity in each region were observed. The lower line is near the edge of the $\mathrm{TiO}_{2}$ film. Delay time in the increasing fluorescence intensity due to the lateral diffusion of the ${ }^{\bullet} \mathrm{OH}$ was clearly observed. To determine the arrival time of the ${ }^{\bullet} \mathrm{OH}$ in the region, the temporal changes of the fluorescence intensity were fitted by a Gaussian distribution. The time at the peak was used as the arrival time of the ${ }^{\bullet} \mathrm{OH}$ molecules in the region. In the plot of the mean-square displacement $\left\langle r^{2}\right\rangle$ against the arrival time of the ${ }^{\bullet} \mathrm{OH}$ molecules in Figure 8 , the first arrival time (ca. $3.2 \mathrm{~s}$ ) was set to $0 \mathrm{~s}$.

\section{References}

(1) Nakamura, R.; Tanaka, T.; Nakato, Y. J. Phys. Chem. B 2004, 108, 10617-10620.

(2) Sato, S. Chem. Phys. Lett. 1986, 123, 126-128.

(3) Livraghi, S.; Paganini, M. C.; Giamello, E.; Selloni, A.; Di Valentin, C.; Pacchioni, G. J. Am. Chem. Soc. 2006, 128, 15666-15671.

(4) Gotić, M.; Ivanda, M.; Sekulić, A.; Musić, S.; Popović, S.; Turković, A.; Furić, K. Mater. Lett. 1996, 28, 225-229. 
(5) Hu, Y.; Tsai, H. L.; Huang, C. L. J. Eur. Ceram. Soc. 2003, 23, 691-696.

(6) Tachikawa, T.; Takai, Y.; Tojo, S.; Fujitsuka, M.; Irie, H.; Hashimoto, K.; Majima, T. J. Phys. Chem. B 2006, 110, 13158-13165.

(7) Mitani, Y.; Shimada, A.; Koshihara, S.; Fukuhara, K.; Kobayashi, H.; Kotani, M. Chem. Phys. Lett. 2006, 431, 164-168.

(8) Hoffmann, M. R.; Martin, S. T.; Choi, W.; Bahnemann, D. W. Chem. Rev. 1995, 95, 69-96.

(9) Li, X.; Chen, C.; Zhao, J. Langmuir 2001, 17, 4118-4122.

(10) Ohno, T.; Masaki, Y.; Hirayama, S.; Matsumura, M. J. Catal. 2001, 204, 163-168.

(11) Takahara, Y. K.; Hanada, Y.; Ohno, T.; Ushiroda, S.; Ikeda, S.; Matsumura, M. J. Appl.

Electrochem. 2005, 35, 793-797. 